\title{
Nitrogênio e enxofre nas características morfogênicas do capim-marandu em substituição ao capim-braquiária em degradação em solo com baixo teor de matéria orgânica ${ }^{1}$
}

\author{
Karina Batista ${ }^{2}$, Francisco Antonio Monteiro ${ }^{3}$
}

\author{
${ }^{1}$ Projeto apoiado pela FAPESP. \\ 2 Programa de Pós-graduação em Solos e Nutrição de Plantas, Av. Dr. Odécio Roland, 631, Jardim Santo André, CEP: 13484-120, \\ Limeira-SP. Bolsista da CAPES. \\ ${ }^{3}$ Departamento Ciência do Solo, Caixa Postal 9, CEP: 13418-900, Piracicaba-SP. Bolsista do CNPq
}

RESUMO - Foi conduzido um experimento em casa de vegetação objetivando avaliar as características morfogênicas da Brachiaria brizantha cv. Marandu, cultivada com doses combinadas de nitrogênio e de enxofre, em um solo (Neossolo Quartzarênico) coletado de uma pastagem em degradação de Brachiaria decumbens. Utilizou-se um esquema fatorial $5^{2}$ fracionado, com 13 combinações das doses de nitrogênio e enxofre (N-S), em mg/dm³ : 0-0; 0-20; 0-40; 100-10; 100-30; 200-0; 200-20; 200-40; 300-10; 300-30; 400-0; 400-20 e 400-40. As unidades experimentais foram distribuídas segundo delineamento em blocos ao acaso, com quatro repetições. Foram realizados três cortes nas plantas. Na implantação do capimmarandu, é fundamental o fornecimento de nitrogênio para o crescimento inicial da planta e estabelecimento da pastagem. Para o capim-marandu, quando o nitrogênio é fornecido em doses entre 300 e $400 \mathrm{mg} / \mathrm{dm}^{3}$, é necessário o mínimo de enxofre de $30 \mathrm{mg} / \mathrm{dm}^{3}$ para a maximização do número de perfilhos e de folhas, da área foliar total e da produção de massa seca da parte aérea da planta. A relação adequada entre as combinações de doses de nitrogênio e de enxofre para a maximização das características morfogênicas do capim-marandu encontra-se no intervalo de 9:1 a 11:1.

Palavras-chave: área foliar, Brachiaria, estabelecimento da pastagem, Neossolo Quartzarênico, perfilho, relação N:S

\section{Nitrogen and sulphur on morphogenic characteristics of marandu palisadegrass replacing signalgrass under degradation in a low organic matter soil}

\begin{abstract}
The experiment was carried out in a greenhouse and aimed to study morphogenic characteristics of Brachiaria brizantha cv. Marandu, grown under combined rates of nitrogen and sulphur, in a soil (Typic Quartzipsamment) collected from a degrading Brachiaria decumbens pasture. A fractionated $5^{2}$ factorial was used, with 13 combinations of nitrogen and sulphur rates (N-S), in $\mathrm{mg} / \mathrm{dm}^{3}: 0-0 ; 0-20 ; 0-40 ; 100-10 ; 100-30 ; 200-0 ; 200-20 ; 200-40 ; 300-10 ; 300-30 ; 400-0$; 400-20; and 400-40, which were set in a randomized block design, with four replications. Plants were harvested three times. Nitrogen supply is essential to obtain both good initial plant growth and pasture establishment with marandu palisadegrass. When nitrogen is applied in rates between 300 and $400 \mathrm{mg} / \mathrm{dm}^{3}$, a minimum sulphur supply of $30 \mathrm{mg} / \mathrm{dm}^{3}$ is necessary to maximize the number of tillers, number of leaves, leaf area, and above-ground dry matter yield of marandu palisadegrass. An adequate ratio for nitrogen and sulphur rates to maximize morphogenic characteristics of this grass ranged from 9:1 to 11:1.
\end{abstract}

Key Words: Brachiaria, leaf area, N:S ratio, pasture establishment, tiller, typic Quartzpsamment

\section{Introdução}

A degradação das pastagens no Brasil tem ocorrido em razão de a produtividade das forrageiras estar muito aquém do potencial produtivo das plantas. Algumas das principais causas são o suprimento inadequado de nutrientes pelos solos de baixa fertilidade e a falta de aplicação de fertilizantes. O suprimento de nutrientes é realizado, na maior parte dos casos, apenas por intermédio da reciclagem de nutrientes via resíduos vegetais ou animais. Neste contexto insere-se a importância do suprimento adequado de nutrientes, e o fornecimento, particularmente, de nitrogênio e enxofre merece destaque pelos efeitos que ambos têm proporcionado às plantas forrageiras.

O conhecimento da influência da disponibilidade de nitrogênio no comportamento produtivo da Brachiaria 
brizantha cv. Marandu é de grande importância para assegurar exploração mais adequada de sua potencialidade, possibilitando maior produção por animal e por unidade de área (Ruggieri et al., 1994). Entretanto, o suprimento de enxofre pode ser inadequado para as gramíneas que crescem em altas doses de nitrogênio (Dijkshoorn \& Lampe, 1960).

O aumento da utilização de adubos concentrados tem reduzido significativamente a adição de enxofre em áreas de cultivo, com efeitos mais agravantes em solos de textura mais arenosa e com baixo teor de matéria orgânica, situados em áreas de alta incidência pluvial. Em condições de baixa disponibilidade desse nutriente, observa-se limitação na produção de massa seca de plantas forrageiras (Santos \& Monteiro, 1999).

A disponibilidade de nitrogênio é o fator dominante que controla os processos de crescimento e desenvolvimento da planta, traduzido, sobretudo, pela maior rapidez de formação das gemas axilares e de iniciação dos perfilhos correspondentes. O déficit de nitrogênio aumenta o número de gemas dormentes, enquanto a adequada nutrição nitrogenada permite o máximo perfilhamento (Nabinger \& Medeiros, 1995). Por outro lado, Santos \& Monteiro (1999), trabalhando com capim-braquiária (Brachiaria decumbens) e doses de enxofre, observaram que as doses de enxofre de 64 e $80 \mathrm{mg} / \mathrm{L}$, na ocasião do segundo crescimento, não diferiram entre si, mas tiveram número de perfilhos superior ao das doses mais baixas de enxofre. Vale ressaltar que uma relação adequada entre as doses de nitrogênio e enxofre foi determinante para o número de perfilhos no primeiro crescimento do capim-braquiária proveniente de uma pastagem em degradação em solo com alto teor de matéria orgânica (Bonfim-Silva \& Monteiro, 2006).

A área foliar também tem sido dependente das combinações de doses de nitrogênio e de enxofre para o capimmarandu (Batista \& Monteiro, 2006) e o capim-braquiária (Bonfim-Silva et al., 2007), evidenciando a importância da relação adequada no fornecimento desses dois nutrientes para plantas forrageiras.

Nesse contexto, objetivou-se avaliar a influência da aplicação de nitrogênio e enxofre, bem como a relação entre as doses desses nutrientes, na produção de folhas e perfilhos, na área foliar total e na produção total de massa seca da parte aérea, para a implantação do capim-marandu em solo ocupado por capim-braquiária em degradação.

\section{Material e Métodos}

O experimento foi conduzido em uma casa de vegetação localizada em Piracicaba, estado de São Paulo, cultivando-se a espécie forrageira $B$. brizantha Stapf. cultivar Marandu, em um Neossolo Quartzarênico, no período de dezembro de 2004 a abril de 2005.

Amostras de um solo com baixo teor de matéria orgânica e com capim-braquiária em estágio de degradação foram coletadas em uma propriedade localizada na Rodovia Piracicaba-Anhembi, no município de Piracicaba. As coordenadas geográficas da área são 4757'56" longitude oeste, $22^{\circ} 46^{\prime} 30$ " latitude sul e a altitude média da região é de $600 \mathrm{~m}$. A coleta do solo foi realizada na profundidade de $0-20 \mathrm{~cm}$ (Monteiro, 2005) e já considerando a quantidade de solo necessária para cada bloco experimental. O solo coletado foi seco à sombra, peneirado e colocado em vasos plásticos contendo $5,5 \mathrm{~kg}$ de solo cada um.

A análise de terra depois de seca e antes da aplicação de qualquer corretivo ou fertilizante apresentou os seguintes resultados: $\mathrm{pH}$ em $\mathrm{CaCl}_{2}=4,08$; matéria orgânica = $11,6 \mathrm{~g} / \mathrm{dm}^{3} ; \mathrm{P}=5,34 \mathrm{mg} / \mathrm{dm}^{3} ; \mathrm{K}=1,75 \mathrm{mmol}_{\mathrm{c}} / \mathrm{dm}^{3} ; \mathrm{Ca}=$ $4,0 \mathrm{mmol}_{\mathrm{c}} / \mathrm{dm}^{3}, \mathrm{Mg}=2,3 \mathrm{mmol}_{\mathrm{c}} / \mathrm{dm}^{3} ; \mathrm{Al}=4 \mathrm{mmol}_{\mathrm{c}} / \mathrm{dm}^{3}$; $\mathrm{H}+\mathrm{Al}=21,5 \mathrm{mmol}_{\mathrm{c}} / \mathrm{dm}^{3} ; \mathrm{S}-\mathrm{SO}_{4}=7,3 \mathrm{mg} / \mathrm{dm}^{3}$; soma de bases $=8,0 \mathrm{mmol}_{\mathrm{c}} / \mathrm{dm}^{3}$; capacidade de troca catiônica = $29,5 \mathrm{mmol} / \mathrm{dm}^{3}$; saturação por bases $=26,8 \%$; $\mathrm{N}$-total $=$ $0,32 \mathrm{~g} / \mathrm{kg} ; \mathrm{N}^{-\mathrm{NO}_{3}}{ }^{-}=21,6 \mathrm{mg} / \mathrm{kg}$ e $\mathrm{N}-\mathrm{NH}_{4}{ }^{+}=24,5 \mathrm{mg} / \mathrm{kg}$. Com base nestes resultados, determinou-se a necessidade de calagem, utilizando-se $50 \%$ para o $\mathrm{V}_{2}$ da fórmula de cálculo da quantidade de corretivo. A calagem foi realizada aplicando-se em cada vaso 0,1822 g de óxido de cálcio e 0,1505 g de óxido de magnésio. Efetuada a calagem, o solo foi umedecido, permanecendo incubado por 31 dias. Após esse período, foi instalado o sistema de irrigação subsuperficial conforme Bonfim-Silva et al. (2007).

O delineamento estatístico foi de blocos ao acaso, com quatro repetições. Foram empregadas cinco doses de nitrogênio $\left(0 ; 100 ; 200 ; 300\right.$ e $\left.400 \mathrm{mg} / \mathrm{dm}^{3}\right)$ e cinco doses de enxofre $\left(0 ; 10 ; 20 ; 30\right.$ e $\left.40 \mathrm{mg} / \mathrm{dm}^{3}\right)$, combinadas em estudo de superfície de resposta, com base em desenho experimental composto central modificado de um fatorial $5^{2}$ incompleto, fundamentado em Littell \& Mott (1975). Assim, utilizaram-se 13 combinações, em $\mathrm{mg} / \mathrm{dm}^{3}$ : 0-0; $0-20 ; 0-40 ; 100-10 ; 100-30 ; 200-0 ; 200-20$; 200-40; 300-10; 300-30; 400-0; 400-20 e 400-40.

Após o período de incubação, procedeu-se à aplicação das doses de nitrogênio e de enxofre, bem como o fornecimento dos demais nutrientes (Tabela 1). As mudas do capim-marandu foram obtidas por germinação de sementes em bandejas com areia lavada e foram transplantadas em número de 15 plântulas por vaso. Uma semana após o transplante das plântulas e aplicação dos nutrientes, observou-se a queima das plântulas, provavelmente devido à pressão osmótica relativamente elevada. Após essa 
Tabela 1 - Quantidades das fontes de nutrientes empregadas em cada combinação de doses de nitrogênio e enxofre

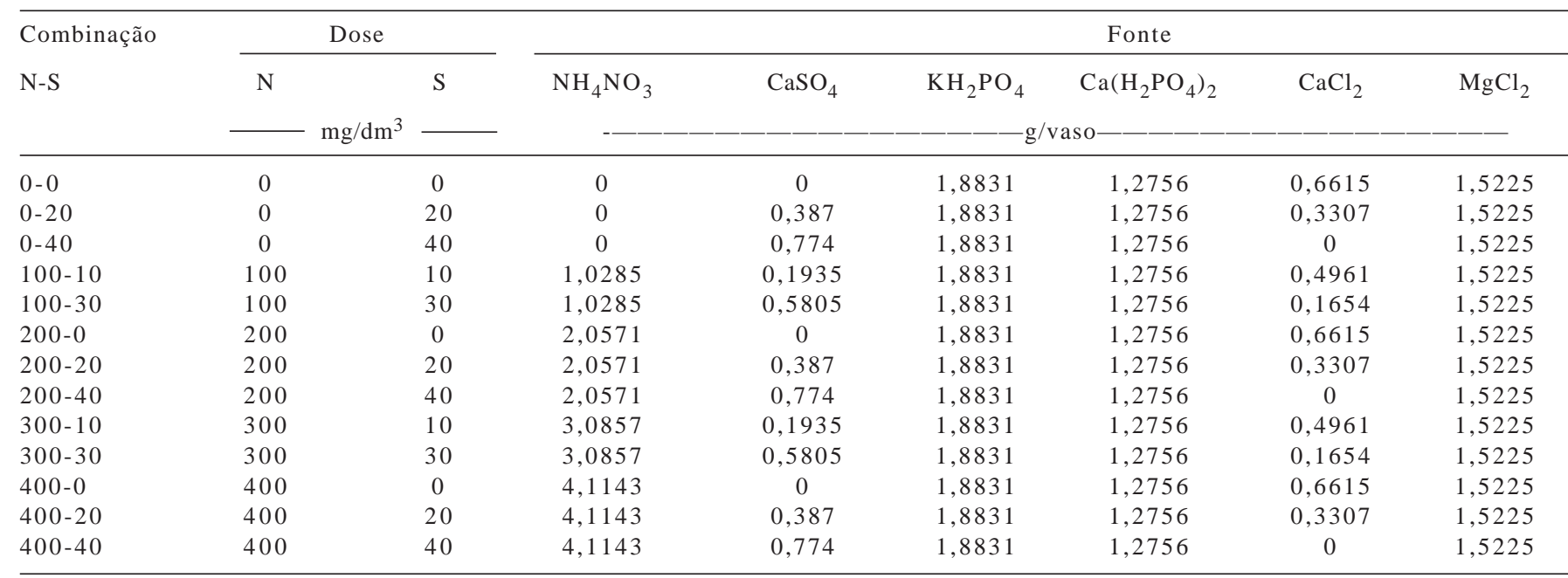

constatação, procedeu-se ao corte das plântulas e posterior lixiviação do solo com água desionizada por um período de 33 dias.

Após a lixiviação do solo e coleta das soluções que geraram a alta pressão osmótica do solo, novas mudas do capim-marandu foram obtidas por germinação de sementes em bandejas com areia lavada e 15 mudas foram transplantadas para cada vaso. Após o período de adaptação das plantas (12 dias), procedeu-se aos desbastes até ficarem cinco plantas em cada vaso, quando as soluções lixiviadas então foram retornadas aos vasos.

Vinte dias após o transplante das plântulas, iniciaram-se as contagens de folhas e perfilhos, que foram efetuadas a cada três dias. Os perfilhos foram contados a partir do momento que possuíam uma folha totalmente expandida e as folhas novas foram computadas a partir do momento que possuíam lígula visível.

Foram realizados três cortes das plantas, com o primeiro ocorrendo aos 38 dias após o transplante das mudas, o segundo aos 27 dias após o primeiro corte e o terceiro aos 38 dias após o segundo corte. Todo o material colhido foi seco em estufa de circulação forçada a $70^{\circ} \mathrm{C}$, até massa constante, com posterior pesagem em balança de precisão.

Após o primeiro e segundo cortes, as aplicações de nitrogênio foram parceladas em quatro vezes, com intervalo de dois dias entre cada aplicação, para evitar variação brusca na pressão osmótica no ambiente radicular. A aplicação de enxofre foi realizada em uma única dose e, posteriormente ao emprego das doses de nitrogênio, aplicaram-se o cloreto de magnésio e o cloreto de cálcio, com intervalo de dois dias entre as aplicações. Os micronutrientes foram fornecidos quatro dias após a aplicação do cloreto de cálcio nas doses: $\mathrm{H}_{3} \mathrm{BO}_{3}=5,1 \mathrm{mg} / \mathrm{vaso}, \mathrm{CuCl}_{2} \cdot 2 \mathrm{H}_{2} \mathrm{O}=9 \mathrm{mg} / \mathrm{vaso}$, $\mathrm{ZnCl}_{2}=7,2 \mathrm{mg} /$ vaso e $\mathrm{Na}_{2} \mathrm{MoO}_{4} \cdot 2 \mathrm{H}_{2} \mathrm{O}=0,9 \mathrm{mg} /$ vaso.

A avaliação da área foliar foi conduzida por meio do integrador de área foliar na ocasião do primeiro, segundo e terceiro cortes das plantas. A área foliar foi medida separadamente para as folhas emergentes, lâminas das duas folhas-recém expandidas e lâminas de folhas maduras. A área foliar de cada unidade experimental foi obtida pela soma da área foliar de cada componente da parte aérea da planta.

Todos os resultados receberam tratamento estatístico, com análise em superfície de resposta (SAS, 1996), adotando-se o nível de 5\% de significância. Inicialmente, foi realizada a análise de variância para as combinações de doses de nitrogênio e enxofre. Em função do nível de significância do teste F para a interação $\mathrm{N} \times \mathrm{S}$, efetuou-se o estudo de regressão polinomial (superfície de resposta) por meio do procedimento RSREG. Quando essa interação não foi significativa, efetuou-se o estudo de regressão de primeiro e segundo graus pelo uso do procedimento GLM.

\section{Resultados e Discussão}

A interação doses de nitrogênio $\times$ doses de enxofre não foi significativa para o número total de perfilhos no primeiro crescimento do capim-marandu, mas foi significativa no segundo e terceiro intervalos de crescimento. Respostas significativas foram observadas para as doses individuais de nitrogênio no número de perfilhos no primeiro intervalo de crescimento do capim, com os resultados ajustando-se ao modelo quadrático de regressão. A dose de nitrogênio de $335 \mathrm{mg} / \mathrm{dm}^{3}$ foi responsável pelo máximo perfilhamento no primeiro crescimento do capim-marandu (Figura 1a). 
a

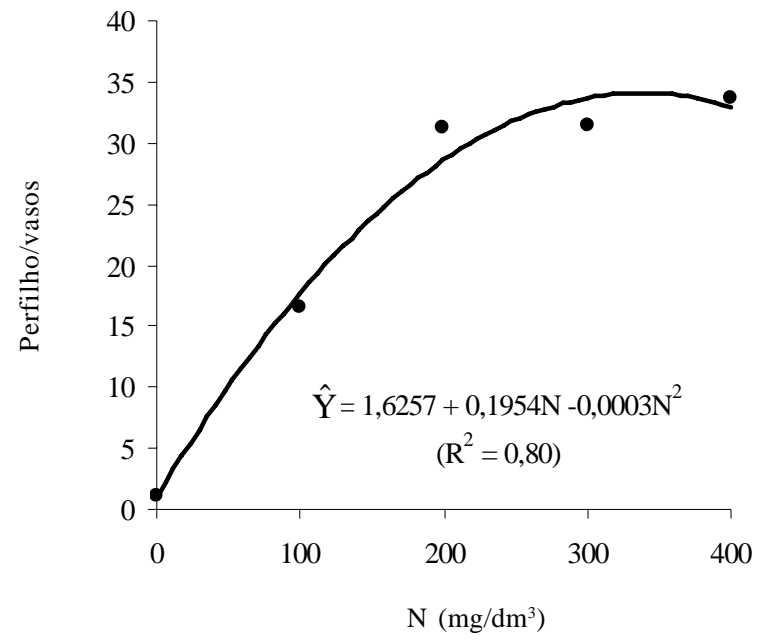

b

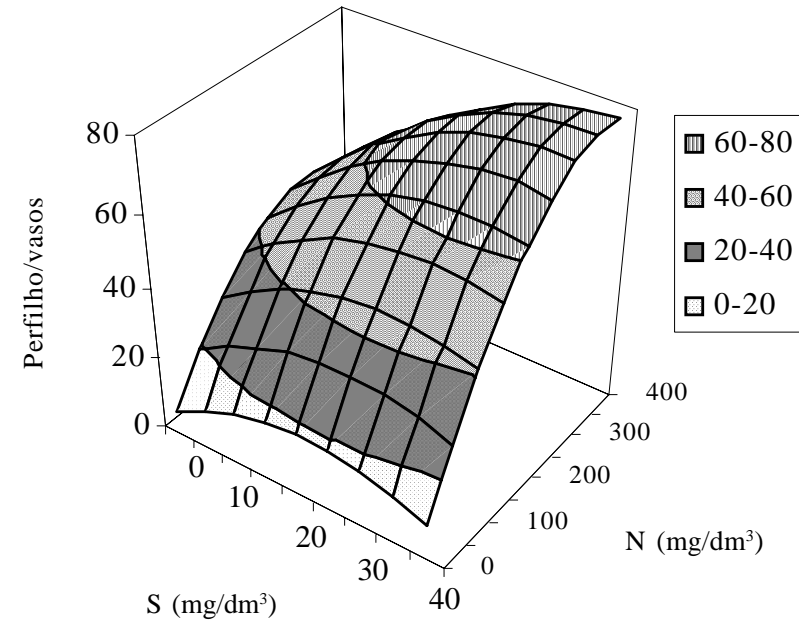

$\hat{\mathrm{Y}}=6,6593+0,2708 \mathrm{~N}-0,0005 \mathrm{~N}^{2}+1,0083 \mathrm{~S}-0,0229 \mathrm{~S}^{2}+0,0021 \mathrm{NS}$ $\left(\mathrm{R}^{2}=0,88\right)$

c

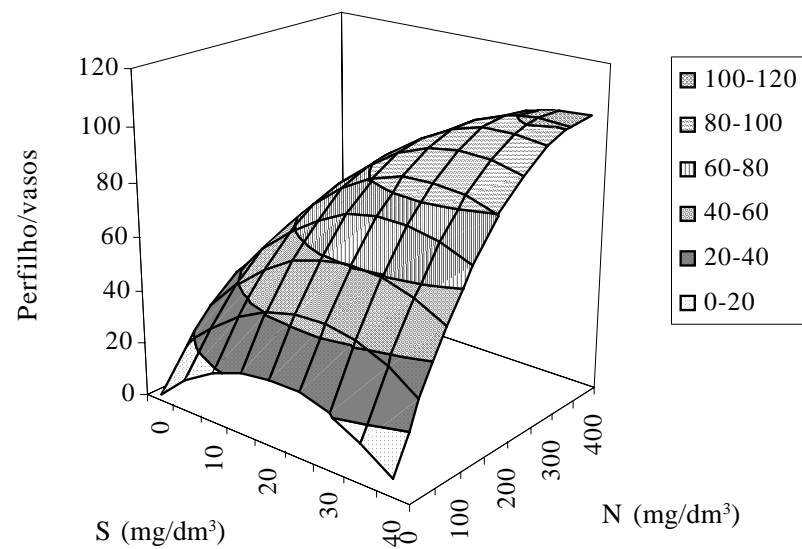

$\hat{\mathrm{Y}}=2,0735+0,3218 \mathrm{~N}-0,0007 \mathrm{~N}^{2}+2,1428 \mathrm{~S}-0,0509 \mathrm{~S}^{2}+0,0044 \mathrm{NS}$ $\left(\mathrm{R}^{2}=0,89\right)$

Figura 1 - Número de perfilhos no primeiro (a), segundo (b) e terceiro (c) cortes do capim-marandu, em função das doses de nitrogênio (a) e das combinações de doses de nitrogênio e enxofre (b e c).
O incremento no número de perfilhos mediante as doses de nitrogênio, com os resultados ajustando-se ao modelo quadrático de regressão, também foi observado por Batista \& Monteiro (2006) com o capim-marandu, ao trabalharem com o fornecimento de doses de nitrogênio (isoladamente ou em combinação com outro macronutriente) em solução nutritiva e para o capim-mombaça, por Manarin (2000) e Lavres Jr. \& Monteiro (2003), em casa de vegetação, e por Braga (2001), em condições de campo.

O nitrogênio e outros fatores ambientais podem influenciar as taxas de aparecimento de folhas, alongamento e senescência foliar, bem como a densidade de perfilhos e o tamanho de folhas (Chapman \& Lemaire, 1993).

As respostas do capim-mombaça a doses de nitrogênio foram estudadas por Garcez Neto et al. (2002), que verificaram influência do nitrogênio no número total de perfilhos produzidos principalmente na rebrotação. Esses autores também observaram que a dose de nitrogênio de $170,5 \mathrm{mg} / \mathrm{dm}^{3}$ foi a responsável pela maior produção de perfilhos.

Na ocasião do segundo intervalo de crescimento, o máximo perfilhamento do capim-marandu ocorreu com a dose de nitrogênio de $370 \mathrm{mg} / \mathrm{dm}^{3}$ associada à dose de enxofre de $39 \mathrm{mg} / \mathrm{dm}^{3}$, na relação entre doses de 9,5:1 (Figura 1b). Vale ressaltar que, em condições de altas doses de enxofre, à medida que se elevaram as doses de nitrogênio, o número perfilhos aumentou, demonstrando que, quanto maior o suprimento de enxofre, maior será a necessidade de nitrogênio para o perfilhamento do capim.

Estes resultados se assemelham àqueles observados por Batista \& Monteiro (2006), no capim-marandu na ocasião do segundo intervalo de crescimento, tendo o capim respondido sempre positivamente às doses de nitrogênio associadas às doses de enxofre. Também Santos \& Monteiro (1999), trabalhando com capim-braquiária submetido a doses de enxofre, observaram que o perfilhamento desse capim foi alterado significativamente pelas doses de enxofre, apenas no segundo crescimento.

Rodrigues et al. (2004), conduzindo experimento em solo proveniente de pastagem degradada, verificaram interação significativa das doses de enxofre, nitrogênio e calcário para o capim-braquiária na ocasião do segundo crescimento. Esses autores relataram que as doses de enxofre de 108 e $216 \mathrm{mg} / \mathrm{kg}$ associadas às doses de nitrogênio de 630 e $1080 \mathrm{mg} / \mathrm{kg}$ resultaram no maior número de perfilhos da gramínea.

O máximo perfilhamento no terceiro crescimento do capim-marandu ocorreu na dose de nitrogênio de $369 \mathrm{mg} / \mathrm{dm}^{3}$ associada à dose de enxofre de $37 \mathrm{mg} / \mathrm{dm}^{3}$, na relação entre doses de 10:1 (Figura 1c). A superfície de 
resposta revelou um platô formado entre as doses de nitrogênio de $350 \mathrm{a} 400 \mathrm{mg} / \mathrm{dm}^{3}$ associadas às doses de enxofre de 35 a $40 \mathrm{mg} / \mathrm{dm}^{3}$.

Como era de se esperar, o número de perfilhos no segundo e terceiro intervalos de crescimento foi mais elevado que o do primeiro crescimento do capim (2,1 e 5,4 vezes, respectivamente). Isto pode ser explicado pelo fato de, no período inicial de crescimento, a planta concentrar a maior parte de sua energia para a formação de seu sistema radicular e da sua parte aérea. No segundo e terceiro períodos de crescimento, a planta já formada possui maior volume radicular (que continuou se desenvolvendo após o primeiro crescimento), com capacidade para absorver maior quantidade de nutrientes para ser metabolizado e também pelo fato de a planta ter sofrido a ação do corte, que acaba promovendo a indução das gemas basais e originando novos perfilhos (Batista \& Monteiro, 2006). Como relatado por Langer (1974), o corte das plantas estimula o perfilhamento, pelo aumento da intensidade luminosa que alcança as gemas basais e pela quebra de dominância apical.

Comparando-se os relatos de Santos \& Monteiro (1999) e Batista \& Monteiro (2006) com os resultados deste experimento pode-se realçar que a ação do enxofre foi melhorada pela presença do nitrogênio. Esses resultados ressaltam ainda a importância da utilização eficiente do nitrogênio, como já discutido por Alvim et al. (2000), para aumentar a produtividade das gramíneas. Por outro lado, Bonfim-Silva \& Monteiro (2006) relataram que, quando o nitrogênio influenciou o perfilhamento do capim-braquiária no segundo e terceiro crescimentos, a interação doses de nitrogênio × doses de enxofre foi significativa para o primeiro crescimento. Isto evidencia que, na implantação do capim-marandu, a relação adequada entre o suprimento de nitrogênio e de enxofre torna-se fundamental para o perfilhamento do capim e fechamento rápido da área da pastagem.

A interação doses de nitrogênio $\times$ doses de enxofre foi significativa para o número total de folhas nos três crescimentos do capim-marandu, com os resultados ajustando-se ao modelo polinomial de regressão (Figura 2).

No primeiro intervalo de crescimento do capim-marandu, o máximo número de folhas seria observado em combinações de doses de nitrogênio e enxofre mais elevadas que as estudadas. Em condições de alta dose de enxofre $\left(40 \mathrm{mg} / \mathrm{dm}^{3}\right)$, associada a incrementos nas doses de nitrogênio, ocorreu aumento na produção de folhas verdes (Figura 2a). Nesse crescimento do capim, a produção máxima de folhas foi 120 vezes maior que a mínima, demonstrando que, quanto maior o suprimento de enxofre, maior a necessidade de nitrogênio pela planta.
No primeiro intervalo de crescimento do capim-marandu, Batista \& Monteiro (2006) também observaram interação significativa doses de nitrogênio $\times$ doses de enxofre. Vale ressaltar que a menor produção de folhas verdes ocorreu nas combinações de baixas doses de nitrogênio para qualquer das doses de enxofre e, à medida que se elevou a dose de nitrogênio, ocorreu aumento na produção de folhas. Ruggieri et al. (1994), Lavres Jr. \& Monteiro (2002) e Batista \& Monteiro (2006) verificaram que o incremento das doses de nitrogênio promoveu aumento na produção de folhas.

A produção máxima de folhas, no segundo crescimento do capim-marandu, ocorreu na combinação de doses de nitrogênio de $348 \mathrm{mg} / \mathrm{dm}^{3}$ associada à dose de enxofre de $38 \mathrm{mg} / \mathrm{dm}^{3}$ (relação entre doses 9,2:1). Em condições de alta dose de enxofre, à medida que se incrementaram as doses de nitrogênio ocorreu aumento na produção de folhas do capim (Figura 2b).

O equilíbrio no fornecimento de nitrogênio e enxofre torna-se de grande importância para a produção de fotossintetizados pela planta, uma vez que, conforme relatado por Chapman \& Lemaire (1993), o número de folhas por perfilho é componente importante para o índice de área foliar, e este é o principal fator que influencia a interceptação da luz pelas plantas numa pastagem.

Batista \& Monteiro (2006) observaram significância para a interação doses de nitrogênio $\times$ doses de enxofre para o número de folhas no capim-marandu, na ocasião do segundo crescimento, em condições de suprimento de nitrogênio e enxofre em solução nutritiva, com as maiores respostas observadas em condições de altas doses de nitrogênio para qualquer dose de enxofre.

O número total de folhas no terceiro crescimento do capim atingiu a produção máxima na dose de nitrogênio de $354 \mathrm{mg} / \mathrm{dm}^{3}$ associada à dose de enxofre de $39 \mathrm{mg} / \mathrm{dm}^{3}$ (relação entre doses 9,0:1). Nas condições da mais alta dose de enxofre (40 mg/ $\mathrm{dm}^{3}$ ), o incremento nas doses de nitrogênio promoveu aumento na produção de folhas. Entretanto, na combinação entre as mais altas doses de nitrogênio $\left(400 \mathrm{mg} / \mathrm{dm}^{3}\right)$ e enxofre $\left(40 \mathrm{mg} / \mathrm{dm}^{3}\right)$, observou-se a formação de um patamar na produção de folhas, confirmando que a aplicação da alta dose de um desses nutrientes demandou alta dose do outro para maximizar o número de folhas do capim (Figura 2c).

Enquanto neste trabalho observou-se a dependência da relação entre as doses de nitrogênio e de enxofre para o estabelecimento do capim-marandu, Bonfim-Silva \& Monteiro (2006) relataram que o capim-braquiária estabelecido e em recuperação, mediante adubação, apresentou 


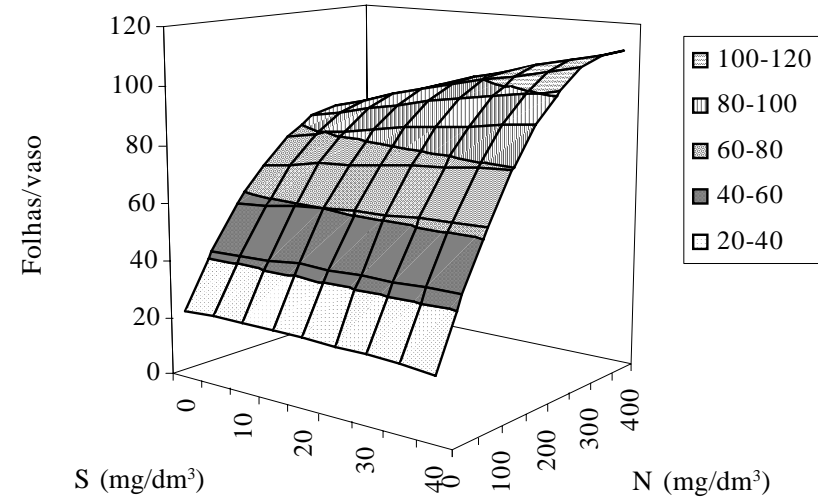

$\hat{\mathrm{Y}}=23,5844+0,3937 \mathrm{~N}-0,0006 \mathrm{~N}^{2}+0,06169 \mathrm{~S}-0,0025 \mathrm{~S}^{2}+$ $0,0020 N S\left(R^{2}=0,94\right)$

b

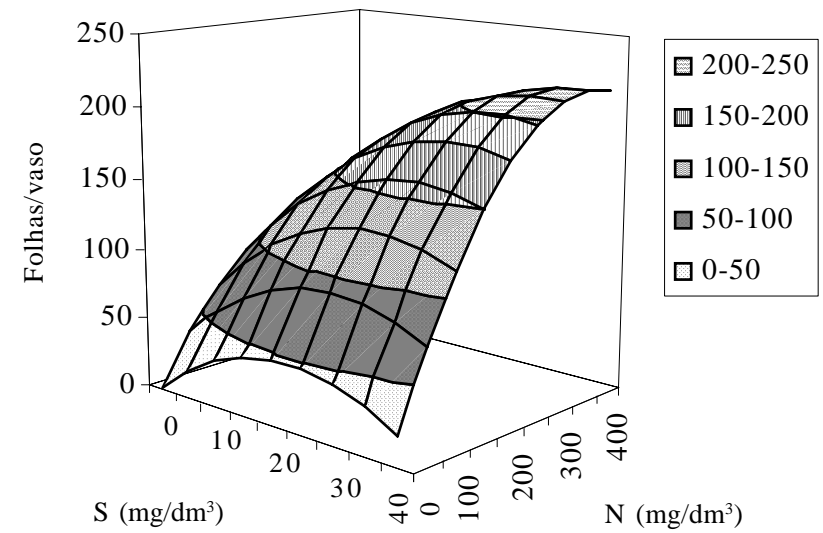

$\hat{\mathrm{Y}}=2,1348+0,7917 \mathrm{~N}-0,0015 \mathrm{~N}^{2}+3,9636 \mathrm{~S}-0,0876 \mathrm{~S}^{2}+$ $0,0076 \mathrm{NS}\left(\mathrm{R}^{2}=0,88\right)$

C

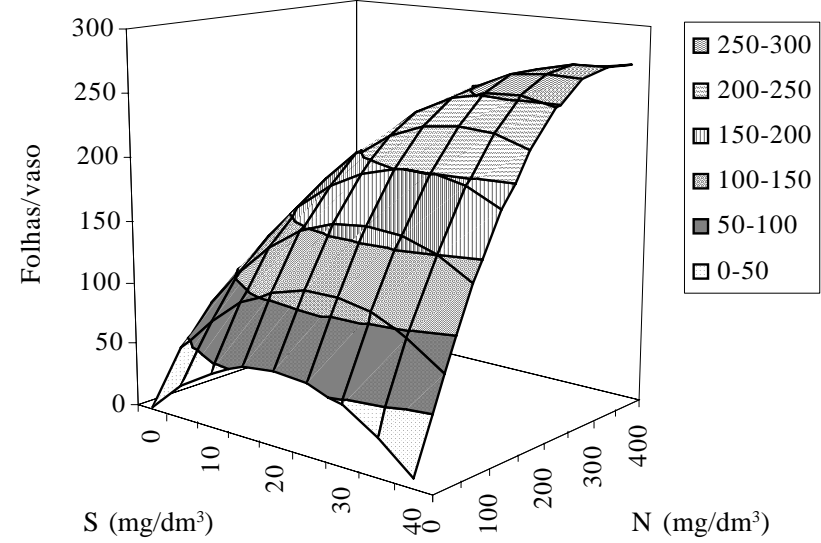

$\hat{\mathrm{Y}}=1,4702+0,9230 \mathrm{~N}-0,0021 \mathrm{~N}^{2}+5,5427 \mathrm{~S}-0,1349 \mathrm{~S}^{2}+$
$0,0139 \mathrm{NS}\left(\mathrm{R}^{2}=0,91\right)$

Figura 2 - Número de folhas no primeiro (a) segundo (b) e terceiro (c) cortes do capim-marandu, em função das combinações de doses de nitrogênio e enxofre. dependência das doses individuais de nitrogênio e de enxofre para o número de folhas.

Garcez Neto et al. (2002), estudando as respostas do capim-mombaça a doses de nitrogênio, revelaram que o número total de folhas aumentou com o suprimento de nitrogênio e que a dose de nitrogênio de $200 \mathrm{mg} / \mathrm{dm}^{3}$ foi a responsável pela maior produção de folhas.

No primeiro crescimento, a área foliar total apresentou significância para as doses individuais de nitrogênio, ajustando-se ao modelo quadrático de regressão (Figura 3a). No segundo e terceiro crescimentos, foi verificada significância para a interação doses de nitrogênio $\times$ doses de enxofre, com ajuste dos resultados ao modelo polinomial de regressão (Figuras 3b e 3c).

A dose de nitrogênio mais elevada que a maior dose aplicada seria necessária para maximizar o valor de área foliar total no primeiro crescimento do capim-marandu. Marschner (1995) ressaltou que o nitrogênio promove alterações na morfologia das plantas, sendo que em condições de alto suprimento de nitrogênio ocorre aumento na área foliar. Chapmam \& Lemaire (1993) descreveram que o nitrogênio proporciona elongação foliar e a área foliar é incrementada.

As respostas em área foliar no primeiro crescimento do capim-marandu diferem daquelas observados por Mattos (2001), com o capim-braquiária, e Batista \& Monteiro (2006), com o capim-marandu. Mattos (2001) observou interação significativa doses de nitrogênio $\times$ doses de enxofre no primeiro crescimento do capim-braquiária proveniente de duas áreas, sendo uma não recentemente adubada e outra recentemente adubada. Batista \& Monteiro (2006) encontraram significância para a interação doses de nitrogênio $\times$ doses de enxofre para o capim-marandu, quando cultivado em solução nutritiva.

Santos Jr. \& Monteiro (2003), trabalhando com capimmarandu, Lavres Jr. \& Monteiro (2003), com capim-aruana, e Silveira (2005), com capim-tanzânia, reportaram que a área foliar foi significativamente alterada pelas doses de nitrogênio fornecidas em solução nutritiva.

O máximo valor de área foliar total na ocasião do segundo crescimento ocorreu na dose de nitrogênio de $384 \mathrm{mg} / \mathrm{dm}^{3}$ associada à dose de enxofre de $38 \mathrm{mg} / \mathrm{dm}^{3}$ (relação entre doses 10,0:1). Doses de nitrogênio acima de $300 \mathrm{mg} / \mathrm{dm}^{3}$ associadas às doses de enxofre superiores a $30 \mathrm{mg} / \mathrm{dm}^{3}$ resultaram em maior valor de área foliar (Figura 3b)

Esses resultados se assemelham àqueles de Batista \& Monteiro (2006), que detectaram interação significativa doses de nitrogênio $\times$ doses de enxofre no segundo crescimento do capim-marandu e ressaltaram que a área foliar 
a

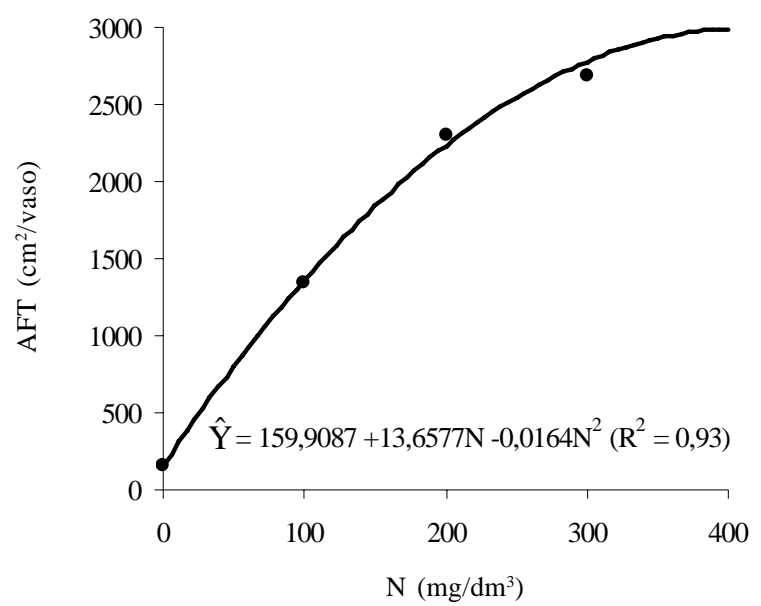

b

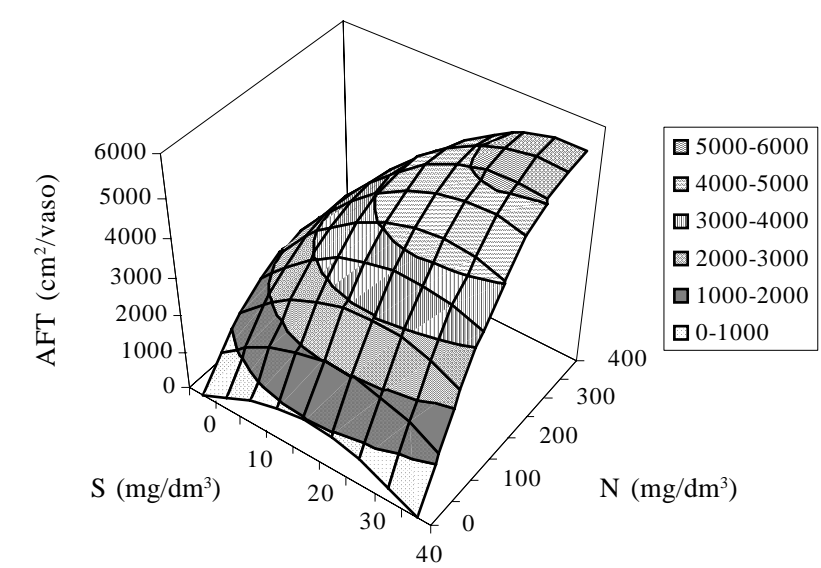

$\hat{\mathrm{Y}}=-165,3449+17,7923 \mathrm{~N}-0,03547 \mathrm{~N}^{2}+110,3461 \mathrm{~S}-2,7132 \mathrm{~S}^{2}+$ $0,2486 \mathrm{NS}\left(\mathrm{R}^{2}=0,88\right)$

c

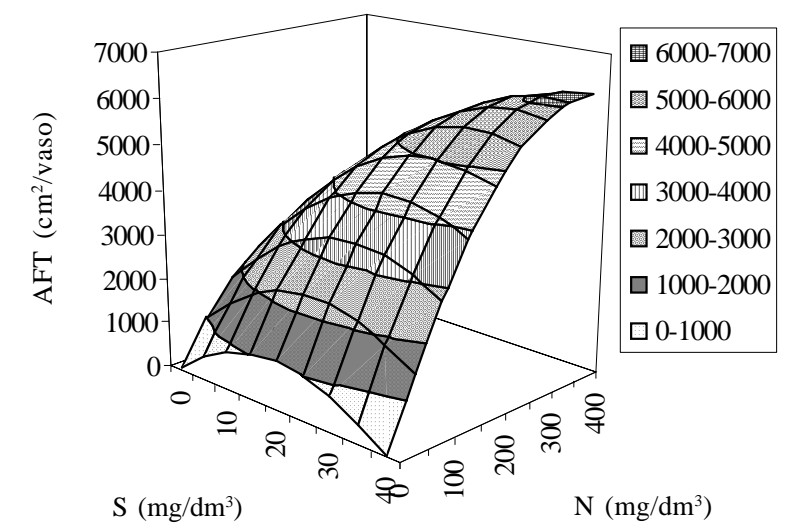

$\hat{\mathrm{Y}}=47,4190+21,3585 \mathrm{~N}-0,0429 \mathrm{~N}^{2}+105,9191 \mathrm{~S}-2,7223 \mathrm{~S}^{2}+$
$0,2809 \mathrm{NS}\left(\mathrm{R}^{2}=0,80\right)$

Figura 3 - Área foliar total (AFT) no primeiro (a), segundo (b) e terceiro (c) cortes do capim-marandu, em função das doses de nitrogênio (a) e das combinações de doses de nitrogênio e enxofre (b e c). nesse crescimento da planta forrageira foi superior ao do primeiro corte. Entretanto, estes resultados diferem daqueles descritos por Mattos (2001), que não observou significância para a interação doses de nitrogênio $\times$ doses de enxofre no segundo crescimento do capim-braquiária estabelecido em pasto em degradação proveniente das áreas não recentemente adubada e recentemente adubada, evidenciando a importância do adequado fornecimento de nitrogênio e enxofre para a implantação do capim-marandu.

Bonfim-Silva et al. (2007) também observaram interação significativa doses de nitrogênio $\times$ doses de enxofre no capim-braquiária. Entretanto, vale ressaltar que o capimbraquiária mostrou-se mais exigente em enxofre $\left(45 \mathrm{mg} / \mathrm{dm}^{3}\right)$ que o capim-marandu, enfatizando mais uma vez a necessidade da adequação específica para o fornecimento de nitrogênio e enxofre entre os capins.

A máxima área foliar total do capim-marandu no terceiro crescimento foi observada na dose de nitrogênio de $376 \mathrm{mg} / \mathrm{dm}^{3}$ combinada com a de enxofre de $39 \mathrm{mg} / \mathrm{dm}^{3}$ (relação entre doses 9,6:1). Em condições de ausência de enxofre, doses elevadas de nitrogênio (acima de $250 \mathrm{mg} / \mathrm{dm}^{3}$ ) promoveram decréscimos no valor de área foliar (Figura 3c). Isto pode ser justificado pelo fato de a deficiência de enxofre promover redução no tamanho e no número de células foliares (Marschner, 1995), o que resulta em diminuição da área foliar.

Estes resultados se assemelham àqueles reportados por Mattos (2001) para o capim-braquiária, que observaram respostas à aplicação de nitrogênio e enxofre e relataram efeito significativo do nitrogênio dentro das doses de enxofre de 0 , 30 e $60 \mathrm{mg} / \mathrm{dm}^{3}$ para o capim proveniente de área não recentemente adubada e significância para as doses de enxofre dentro das doses de nitrogênio de 50, 100 e $200 \mathrm{mg} / \mathrm{dm}^{3}$ para o capim de área recentemente adubada.

A interação doses de nitrogênio $\times$ doses de enxofre foi significativa para a produção de massa seca da parte aérea nos três cortes do capim-marandu, com ajuste dos resultados a modelo polinomial de regressão (Figura 4).

Para a produção de massa seca da parte aérea no primeiro corte do capim, ocorreu um ponto de sela e, dessa maneira, o máximo valor de produção de massa seca não pode ser determinado. Entretanto, as produções máximas de massa seca da parte aérea estariam localizadas entre as doses de nitrogênio de 300 a $400 \mathrm{mg} / \mathrm{dm}^{3}$ associadas às doses de enxofre de 30 a $40 \mathrm{mg} / \mathrm{dm}^{3}$ (Figura 4a).

Mattos (2001) também observou significância para a interação doses de nitrogênio $\times$ doses de enxofre no primeiro crescimento do capim-braquiária proveniente de duas áreas de pastagens. A mais alta produção de massa seca do capim-braquiária proveniente de área não recentemente 
adubada foi alcançada mediante o suprimento de nitrogênio de $192 \mathrm{mg} / \mathrm{dm}^{3}$ em presença da dose de enxofre de $60 \mathrm{mg} / \mathrm{dm}^{3}$. Para o capim-braquiária proveniente de área recentemente adubada, esse autor relatou que o nitrogênio fornecido foi mais eficientemente convertido em massa pela forrageira nas doses de enxofre de 30 e $60 \mathrm{mg} / \mathrm{dm}^{3}$.

Batista \& Monteiro (2006) constataram resultados semelhantes para a produção de massa seca da parte aérea no primeiro corte do capim-marandu e enfatizaram que, em condições de baixas doses de nitrogênio, mesmo com o incremento das doses de enxofre, a produção de massa seca da parte aérea permanecia constante, mas, à medida que se aumentaram as doses de nitrogênio associadas às doses de enxofre, foi incrementada a produção de massa seca.

Monteiro et al. (1995) observaram reduções significativas na produção de massa seca do capim-marandu cultivado em solução nutritiva no tratamento em que se omitiu enxofre, quando comparado ao tratamento completo. Por outro lado, Marques et al. (1995) observaram que a não aplicação de enxofre não interferiu no rendimento total de massa seca da parte aérea do capim-marandu quando cultivado na microregião de Campos da Mantiqueira - MG.

A máxima produção de massa seca da parte aérea no segundo corte do capim-marandu ocorreu na combinação de doses de nitrogênio de $382 \mathrm{mg} / \mathrm{dm}^{3}$ associada à dose de enxofre de $36 \mathrm{mg} / \mathrm{dm}^{3}$, na relação entre doses de 10,6:1. Em condições de baixa dose de enxofre, ao se incrementar o fornecimento de nitrogênio não ocorreu aumento na produção de massa seca da parte, enquanto, em condições de alta dose de enxofre, o aumento no suprimento de nitrogênio resultou em elevação na produção de massa seca da parte aérea. Isto demonstra mais uma vez a necessidade do equilíbrio entre o fornecimento de nitrogênio e enxofre para a gramínea forrageira (Figura 4b).

Na ocasião do terceiro corte, a máxima produção de massa seca da parte aérea ocorreria em uma dose de nitrogênio mais elevada que a máxima estudada no experimento associada à dose de enxofre de $39 \mathrm{mg} / \mathrm{dm}^{3}$. Quando o enxofre foi fornecido em altas doses (25 a $\left.40 \mathrm{mg} / \mathrm{dm}^{3}\right)$, o aumento na produção de massa seca pode ser totalmente creditado ao suprimento de nitrogênio (Figura 4c).

A produção de massa seca no terceiro corte foi maior em relação ao primeiro e segundo cortes, efeito que pode ser atribuído à necessidade maior de energia no primeiro crescimento para a estrutura da parte aérea e o desenvolvimento e formação do sistema radicular.

A importância do suprimento com nitrogênio para o capim-marandu também foi ressaltada por Abreu \& Monteiro (1999), ao relatarem que as produções de massa seca da parte aérea do capim-marandu, avaliadas aos 14, 28 e 42

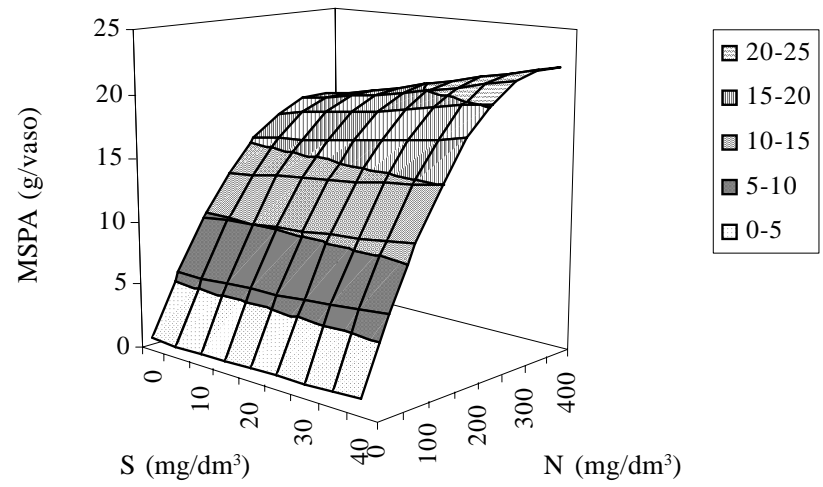

$\hat{\mathrm{Y}}=0,8957+0,1040 \mathrm{~N}-0,0002 \mathrm{~N}^{2}-0,0040 \mathrm{~S}-0,0004 \mathrm{~S}^{2}+$

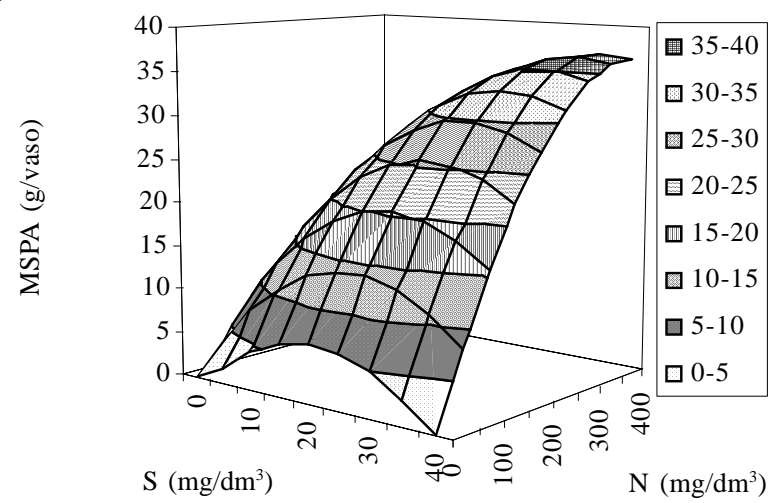

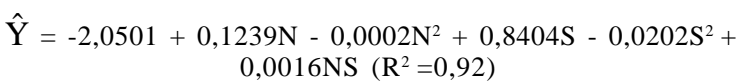

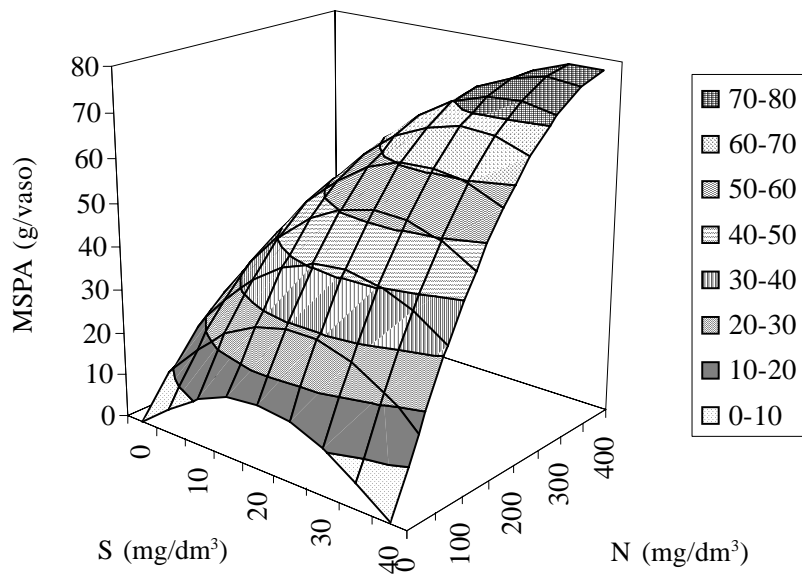

$\hat{\mathrm{Y}}=-1,5376+0,2286 \mathrm{~N}-0,0005 \mathrm{~N}^{2}+1,6322 \mathrm{~S}-0,0410 \mathrm{~S}^{2}$ $+0,0038 \mathrm{NS}\left(\mathrm{R}^{2}=0,89\right)$

Figura 4 - Massa seca da parte aérea (MSPA) no primeiro (a), segundo (b) e terceiro (c) cortes do capim-marandu, em função das combinações de doses de nitrogênio e enxofre. 
dias do crescimento inicial, variaram significativamente com as doses de nitrogênio, observando-se as máximas produções nas doses de 140, 152 e $190 \mathrm{mg} / \mathrm{kg}$. Manarin (2000) relatou que a produção de massa seca da parte aérea do capim-mombaça variou com as doses de nitrogênio nos cortes realizados aos 29 dias após o transplante das mudas e aos 26 dias após o primeiro corte.

A significância para a interação doses de nitrogênio $\times$ doses de enxofre observada nos três cortes do capimmarandu enfatiza o descrito por Raij (1991), que plantas deficientes em enxofre apresentam crescimento lento, mesmo havendo suprimento adequado de nitrogênio.

\section{Conclusões}

Na implantação do capim-marandu, em área ocupada anteriormente por capim-braquiária, é fundamental o fornecimento de nitrogênio para o crescimento inicial da planta e estabelecimento da pastagem. Com o fornecimento de nitrogênio em doses entre 300 e $400 \mathrm{mg} / \mathrm{dm}^{3}$, é necessário aplicar o mínimo de enxofre de $30 \mathrm{mg} / \mathrm{dm}^{3}$, para maximização do número de perfilhos e folhas, da área foliar total e da produção de massa seca da parte aérea. A relação adequada entre as combinações de doses de nitrogênio e enxofre para a maximização da produção do capim-marandu encontra-se no intervalo de doses de 9:1 a 11:1.

\section{Agradecimento}

À FAPESP, ao CNPq, ao proprietário da Agropecuária Rodomeu e aos pós-graduandos e graduandos do Grupo de Nutrição Mineral de Plantas da ESALQ - USP.

\section{Literatura Citada}

ABREU, J.B.R.; MONTEIRO, F.A. Produção e nutrição do capimMarandu em função de adubação nitrogenada e estádios de crescimento. Boletim de Indústria Animal, v.56, n.2, p.137146, 1999.

ALVIM, M.J.; XAVIER, D.F.; VERNEQUE, R.S. et al. Resposta do Tifton 68 a doses de nitrogênio e a intervalos de cortes. Pesquisa Agropecuária Brasileira, v.35, n.9, p.1875-1882, 2000.

BATISTA, K.; MONTEIRO, F.A. Respostas morfológicas e produtivas do capim-marandu adubado com doses combinadas de nitrogênio e enxofre. Revista Brasileira de Zootecnia, v.35, n.4, p.1281-1288, 2006.

BONFIM-SILVA, E.M.; MONTEIRO, F.A. Nitrogênio e enxofre em características produtivas do capim-braquiária de área de pastagem degradada. Revista Brasileira de Zootecnia, v.36, n.4, p.1289-1297, 2006.

BONFIM-SILVA, E.M.; MONTEIRO, F.A.; SILVA, T.J.A. Nitrogênio e enxofre na produção e no uso de água pelo capimbraquiária em degradação. Revista Brasileira de Ciência do Solo, v.31, n.2, p.309-317, 2007.
BRAGA, G.J. Resposta do capim-Mombaça (Panicum maximum Jacq.) a doses de nitrogênio e intervalos de corte. Pirassununga: Faculdade de Zootecnia e Engenharia de Alimentos, 2001. 121p. Dissertação (Mestrado em Zootecnia) - Faculdade de Zootecnia e Engenharia de Alimentos, 2001.

CHAPMAN, D.F.; LAMAIRE, G. Morphogenetic and structural determinants of plant regrowth after defoliation. In: INTERNATIONAL GRASSLAND CONGRESS, 17., 1993, Palmerston North. Proceedings... Palmerston North: New Zealand Grassland Association, 1993. p.95-104.

DIJKSHOORN, W.; LAMPE, J.E.M. A method of diagnosing the sulphur nutrition status of herbage. Plant and Soil, v.13, n.3, p.227-241, 1960.

GARCEZ NETO, A.F.G.; NASCIMENTO JR., D.; REGAZZI, A.J. et al. Respostas morfogênicas e estruturais de Panicum maximum cv. Mombaça sob diferentes níveis de adubação nitrogenada e alturas de corte. Revista da Sociedade Brasileira de Zootecnia, v.31, n.5, p.1890-1900, 2002.

LANGER, R.H.M. Tillering in herbage grasses. Herbage Abstracts, v.33, n.3, p.141-148, 1974.

LAVRES JR., J.; MONTEIRO, F.A. Combinações de doses de nitrogênio e potássio para a produção e nutrição do capimMombaça. Boletim de Indústria Animal, v.59, n.2, p.101114, 2002.

LAVRES JR., J.; MONTEIRO, F.A. Perfilhamento, área foliar e sistema radicular do capim-Mombaça submetido a combinações de doses de nitrogênio e potássio. Revista Brasileira de Zootecnia, v.32, n.5, p.1068-1075, 2003.

LITTELL, R.C.; MOTT, G.O. Computer assisted design and analysis of response surface experiments in agronomy. Soil and Crop Society of Florida Proceedings, v.34, n.5, p.94-97, 1975.

MANARIN, C.A. Respostas fisiológicas, bioquímicas e produtivas do capim-Mombaça a doses de nitrogênio. Piracicaba: Escola Superior de Agricultura "Luiz de Queiroz", 2000. 59p. Dissertação (Mestrado em Solos e Nutrição de Plantas) - Escola Superior de Agricultura "Luiz de Queiroz", 2000.

MARQUES, J.J.G.S.M.; CURI, N.; FAQUIN, V. et al. Limitações nutricionais para gramíneas forrageiras em Cambissolo álico da Microregião Campos da Mantiqueira-MG, Brasil. Produção de matéria seca e perfilhamento. Pasturas Tropicales, v.17, n.3, p.12-16, 1995.

MARSCHNER, H. Mineral nutrition of higher plants. 2.ed. London: Academic Press, 1995. 889p.

MATTOS, W.T. Avaliação de pastagem de capim-braquiária em degradação e sua recuperação com suprimento de nitrogênio e enxofre. Piracicaba: Escola Superior de Agricultura "Luiz de Queiroz”, 2001. 97p. Tese (Doutorado em Solos e Nutrição de Plantas) - Escola Superior de Agricultura "Luiz de Queiroz", 2001.

MONTEIRO, F.A. Amostragem de solo e planta para fins de análises químicas: métodos e interpretação de resultados. In: SIMPÓSIO SOBRE MANEJO DA PASTAGEM, 22., 2005, Piracicaba. Anais... Piracicaba: Fundação de Estudos Agrários Luiz de Queiroz, 2005. p.151-179.

MONTEIRO, F.A.; RAMOS, A.K.B.; CARVALHO, D.D. et al. Cultivo de Brachiaria brizantha Stapf. cultivar Marandu em solução nutritiva com omissão de macronutrientes. Scientia Agricola, v.52, n.1, p.135-141, 1995.

NABINGER, C.; MEDEIROS, R.B. Produção de sementes de Panicum maximum Jacq. In: SIMPÓSIO SOBRE MANEJO DA PASTAGEM, 14., 1992, Piracicaba. Anais... Piracicaba: Fundação de Estudos Agrários Luiz de Queiroz, 1995. p.59-128.

RAIJ, B. van. Fertilidade do solo e adubação. Piracicaba: Ceres, 1991. 343p.

RODRIGUES, R.C.; PEREIRA, W.L.; ANDREOTTI, N.F. et al. Perfilhamento do capim-braquiária cultivado em solo proveniente de uma pastagenm degradada em função das doses de nitrogênio, enxofre e calcário. Boletim de Indústria Animal, v.61, n.1, p.39-47, 2004. 
RUGGieri, A.C.; FAVORETtO, V.; MALheiros, E.B. Características de crescimento e produção de matéria seca da Brachiaria brizantha (Hochst) Stapf. cv. Marandu em função de níveis de nitrogênio e regimes de corte. Boletim de Indústria Animal, v.51, n.2, p.149-155,1994.

SANTOS, A.R.; MONTEIRO, F.A. Produção e perfilhamento de Brachiaria decumbens Stapf. em função de doses de enxofre. Scientia Agricola, v.56, n.3, p.689-692, 1999.

SANTOS JR., J.D.G.; MONTEIRO, F.A. Nutrição em nitrogênio do capim-Marandu submetido a doses de nitrogênio e idades de crescimento. Boletim de Indústria Animal, v.60, n.1, p.139146, 2003.

SILVEIRA, C.P. Mineralização da produção e nutrição mineral do capim-Tanzânia com variável disponibilidade de nitrogênio e cálcio. Piracicaba: Escola Superior de Agricultura "Luiz de Queiroz", 2005. 87 p. Dissertação (Mestrado em Solos e Nutrição de Plantas) - Escola Superior de Agricultura “Luiz de Queiroz”, 2005.

STATISTICAL ANALYSIS SYSTEM - SAS. The SAS-system for windows: release 6.08 (software). Cary: SAS Institute, 1996. (CD-ROM). 